Technological University Dublin

DƯBLIN

ARROW@TU Dublin

\title{
The Role of Role-Play in Student Awareness of the Social Dimension of the Engineering Profession
}

\author{
Diana Adela Martin \\ dianaadela.martin@tudublin.ie \\ Eddie Conlon \\ edward.conlon@tudublin.ie \\ Brian Bowe \\ Brian.Bowe@TUDublin.ie
}

Follow this and additional works at: https://arrow.tudublin.ie/schmuldistart

Part of the Other Engineering Commons

\section{Recommended Citation}

Martin,D.A., Conlon, E. \& Bowe, B. (2019) The role of role-play in student awareness of the social

dimension of the engineering profession, European Journal of Engineering Education, 44:6, 882-905, DOI:

$10.1080 / 03043797.2019 .1624691$

This Article is brought to you for free and open access by the School of Multidisciplinary Technologies at ARROW@TU Dublin. It has been accepted for inclusion in Articles by an authorized administrator of ARROW@TU

Dublin. For more information, please contact arrow.admin@tudublin.ie, aisling.coyne@tudublin.ie, gerard.connolly@tudublin.ie.

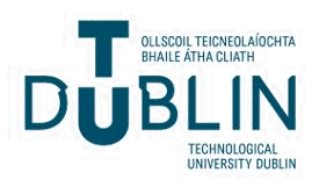




\section{The role of role-play in student awareness of the social dimension of the engineering profession}

\section{Diana Adela Martin, Eddie Conlon \& Brian Bowe}

To cite this article: Diana Adela Martin, Eddie Conlon \& Brian Bowe (2019) The role of role-play in student awareness of the social dimension of the engineering profession, European Journal of Engineering Education, 44:6, 882-905, DOI: 10.1080/03043797.2019.1624691

To link to this article: https://doi.org/10.1080/03043797.2019.1624691

\section{曲 Published online: 31 May 2019.}

Submit your article to this journal ๘

Џlll Article views: 144

Q View related articles $\asymp$

View Crossmark data ¿ 


\title{
The role of role-play in student awareness of the social dimension of the engineering profession
}

\author{
Diana Adela Martin $\mathbb{1}^{\mathrm{a}}$, Eddie Conlon ${ }^{\mathrm{a}}$ and Brian Bowe ${ }^{\mathrm{b}}$

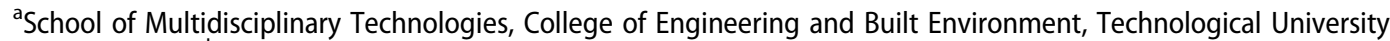 \\ Dublin, Ireland; ${ }^{\mathrm{b}}$ Technological University, Dublin, Ireland
}

\begin{abstract}
The article aims to expand upon traditional case based instruction through role-play and to explore the effectiveness of the approach in raising students' awareness of the social dimension of the engineering profession. For this purpose, we added a contextual description to the case study Cutting Roadside Trees driven by a macroethical outlook. Our contribution draws on an exercise based on the contextualised case study in which 80 students at Technological University Dublin participated. The results gathered show that role-playing contributed to complex student responses to the scenario and an awareness of the social factors that are part of engineering practice and which can constrain or enable decision-making. We suggest that exposing students to the perspectives of the different stakeholders that are involved in engineering professional practice can contribute to their understanding of the social context of engineering practice.
\end{abstract}

\section{ARTICLE HISTORY}

Received 2 May 2018

Accepted 22 May 2019

\section{KEYWORDS}

Engineering ethics; macroethics; role-play; case studies; professional practice

\section{Introduction}

Case studies are the prevalent teaching method employed in engineering ethics education, but despite their popularity, there is little or no empirical evidence supporting their effectiveness compared to other teaching methods (Herkert 2000; Colby and Sullivan 2008; Barry and Ohland 2009; Yadav and Barry 2009; Abaté 2011). The most common use of case studies is within a microethical frame, focused on describing individual dilemmas set in scenarios of crisis that can be solved through the application of ethical heuristics and by appealing to the precepts of professional codes and ethical theories (Haws 2001). There is little concern with incorporating macroethical aspects such as public policy and the broader social mission of engineering (Colby and Sullivan 2008; Bielefeldt et al. 2016).

Recently, the microethical use of case studies for teaching engineering ethics has attracted criticism pointing to its inadequacy in capturing the complexity of the profession (Lynch and Kline 2000; Bucciarelli 2007; Conlon and Zandvoort 2011). This article aims to expand upon traditional case based instruction through the integration of role-play elements, exploring the effectiveness of the approach in enhancing students' awareness of the social dimension of the engineering profession. For this aim, we added a contextual description to the case study Cutting Roadside Trees (Pritchard 1992), driven by a macroethical outlook. Our contribution draws on an exercise based on the contextualised case study in which 80 first year students at Technological University Dublin ${ }^{1}$ participated. The data gathered shows that role-playing contributed to complex student responses to the scenario, revealing a heightened awareness of the social factors that are part of engineering practice and which can 
constrain or enable an engineer's agency. The role-play based on the contextualised case study Cutting Roadside Trees led to (i) more diversity of solutions proposed, (ii) students' awareness of the value laden nature of engineering solutions, and (iii) an acknowledgment of the social dynamics in engineering decision-making, involving a need for compromise but also an acknowledgment of the power associated with different roles.

We proceed by looking at the beginnings of case instruction, highlighting its main characteristics and benefits according to empirical research. We then focus on the use of case studies for engineering ethics instruction, presenting four deficiencies of current approaches. We claim that these deficiencies are rooted in a microethical approach to engineering ethics education, which leads to a dilution of some of the major features of case pedagogy. The next section puts forward a macroethical proposal for integrating role-play in the case study Cutting Roadside Trees in a manner that aims to address the deficiencies of case pedagogy previously identified, followed by a discussion in the final section of the results of putting the exercise into practice.

\section{Case study pedagogy: characteristics and benefits}

Case studies were first used as a teaching method in law and business, their history tracing back to the law professor and dean of Harvard Law School Christopher Langdell, who first taught a case study in 1870 . The cases designed by Langdell were inspired by real sources and were meant to encourage students' independent thinking, thus moving away from the lecture and recitation format focused on presenting information and then asking students to memorise it (Garvin 2003). Harvard Business School adopted the method almost 100 years ago, in 1920, under the leadership of Wallace Brett Donham, himself a law graduate (Herreid 1994). With Donham as dean, the school developed approximatively 18000 cases during a 27 year span, making famous the pedagogical method that is now called the Harvard Case Method (Bridgman, Cummings, and McLaughlin 2016).

How case studies are conceptualised and taught varies between disciplines (Barton 2007). The dialogical format of case studies became the mark of legal education (Parker and Evans 2007). In management modules, decision-making is predominantly taught via case studies and not through theory (Barton 2007). In the medical field, case studies developed as problem based learning, with students receiving patient records that require the application of scientific knowledge in order to formulate diagnostic hypotheses or propose treatment protocols (Barrows and Tamblyn 1980; Williams 1992). Although the case study method is not the same as problem based learning, both approaches are inductive in nature, drawing inferences from particular instances and empirical observations. The inductive format proved suitable in addressing ill-structured problems like those typically arising in law, business and medicine, such that case centred pedagogy grew to become a widespread teaching method in these fields (King and Kitchener 1994; Garvin 2003). Although engineering is a discipline traditionally associated with deductive teaching methods (Prince and Felder 2006), case studies began to be developed in the 1960s at Stanford University, leading to the creation of the first library of case studies (Richards et al. 1995).

Besides their inductive format, other important characteristics of case studies are ill-structure, verisimilitude, extensiveness, context driven, ambiguity and complexity, multidimensional perspective and interactivity.

\subsection{III-structure}

Case studies are considered to support the formulation of ill-structured problems. Kitchener (1983) defines ill-structured problems as allowing conceptualisation of multiple - sometimes opposing - solutions, which means there is 'no explicit means for determining appropriate action' (Jonassen 1997, 69). In the absence of generalisable principles and a directive theory, contextual factors play a significant role that can both shape and constrain action. The problems presented by case studies can contain 'uncertainty about which concepts, rules, and principles are necessary for the solution or 
how they are organized' (Ibid.). Thus, case studies evade deductive approaches that rely on inferences from general theories towards an anticipated solution which is logically sound.

\subsection{Verisimilitude}

Case studies are meant to closely reflect features of a profession. They are expected to contain authentic problems a practitioner might encounter, making the students aware of the complex nature of the profession (Davis 1997; Raju and Sankar 1999; Davis and Yadav 2014).

\subsection{Extensive scope}

Aldridge $(1994,234)$ notes that a case study is 'more general in its framework and purpose than a normal engineering problem, including the interaction of engineering and non-engineering topics'. As opposed to typical well-structured problem sets often employed in mathematics, science or engineering pedagogy that rely on concrete and quantitative data, case studies are envisioned to include additional aspects that are part of professional practice. Besides technical information, case studies also convey qualitative or abstract information (Merseth 1990), giving rise to a rich description of the situation they portray.

\subsection{Context driven}

Thus given their extended scope and realistic character, case studies have a significant contextual component (Williams 1992; Davis 2005). This can include information about the various stakeholders involved in the design and decision process of an engineering project and their interaction, socio political and economic attributes of the environment in which the project is set, as well as the pressure these give rise to, organisational details, socio-cultural expectations or policy agendas (Fuchs 1974; Jonassen 1999). Context gains a crucial importance in setting the case study, given that it can restrain individual agency or shape the decision-making process for achieving the desired resolution. Different contextual information can lead to different strategies for tackling the scenario presented by the case study, allowing even the possibility that no strategy is entirely satisfactory.

\subsection{Ambiguity and complexity}

Case studies can tolerate or cultivate ambiguity and complexity. This means there is no predetermined strategy or theory that can be applied to reach a desired solution, as well as no predetermined ideal outcome. Case studies contain a wide range of contextual information, often ambiguous, leading to a lack of clarity whether one or another specification or constraint should weigh in when deciding on the strategy to be pursued, or how each factor can affect the outcome. Case studies should incorporate 'the complexities and ambiguities of real-world ethical problems in an effective and memorable way' (Stephan 2001-2, 11), in order to enhance students' understanding of the decision-making process as it happens in a professional setting (Kim et al. 2006; Swanson and Morrison 2010).

\subsection{Multidimensional perspective}

As such, case studies are envisioned to trade off certainty for nuances. The lack of a definite absolute solution or a predetermined solution path means that a problem can be represented in various ways, and the perspectives of multiple subjects influence the design and decision-making process. Jonassen $(1997,81)$ remarks that 'ill-structured problems possess multiple solutions because there are multiple representations of the problem', and it is the personal perspective on the constraints faced that influences which resolution is favoured. Thus, case studies can make students aware of the different 
viewpoints that come to shape the decision-making process in a professional setting and the need to take into account the perspectives of different participants or stakeholders (Kim et al. 2006). Unlike textbook problems that assume a single objective viewpoint, in the formulation of case studies various stances are voiced, such that when formulating a case study, 'every attempt is made to provide an unbiased multidimensional perspective' (Merseth 1990, 54).

\subsection{Interactivity}

Case studies allow interactions. The inclusion of different perspectives in the problem description means that unlike textbook problems, case studies are dynamic. The solution emerges out of a wide array of factors and subjective viewpoints that interact in the design and decision-making process of an engineering project. The scenarios presented by case studies can thus be enacted by participants to simulate such interactions (Lundeberg 2008).

The popularity of case instruction is supported by empirical evidence in favour of their benefits. Research focused on case instruction highlighted several benefits. Case studies are considered to contribute to enhancing students' critical-thinking skills, the ability to synthesise complex analytical questions and connect theoretical issues with real life practice, as well as analyzing an issue from multiple perspectives in medical studies (Thomas et al. 2001; Thistlethwaite et al. 2012), business (Pilz and Zenner 2018), science (Bonney 2015) and engineering education (Yadav et al. 2007).

\section{Case studies in engineering ethics education}

In regards to the use of case studies in teaching engineering ethics, there is little or no empirical evidence proving its effectiveness compared to other teaching methods (Barry and Ohland 2009; Yadav and Barry 2009). There is also limited empirical research available that would identify 'the mechanism by which the case study method is able to achieve its alleged superiority as a pedagogical model' in the area of engineering ethics (Abaté 2011, 589), as well as on the effectiveness of different types of case content that could serve as guidance to engineering ethics instructors (Bagdasarov et al. 2013; Thiel et al. 2013, 267). Nevertheless, case study pedagogy is the prevalent method employed in teaching ethics in engineering colleges in the U.S. (Herkert 2000; Colby and Sullivan 2008; Freyne and Hale 2009; Yadav and Barry 2009; Hess and Fore 2018). Hess and Fore (2018) also note that there is some degree of confusion about the purposes of ethics education, but the goals they identify from their empirical work, such as ethical sensitivity, awareness, judgement, imagination, courage, commitment and helping students to reason or act ethically, have an overriding focus on the moral agency of engineers and less on the context in which they may have to make ethical decisions.

Herkert $(2005,373)$ has argued that there are two major frames for teaching engineering ethics: a microethical approach focused on ethical dilemmas faced by individual engineers, and a macroethical approach concerned with 'the collective responsibilities of the profession and societal decisionmaking about technology'. The goal of microethics is refining moral reasoning and developing moral character. The macroethical approach treats engineers as members of social, political or organisational structures. Its aim is to help engineers focus on the broader ethical obligations of the profession, such as promoting sustainable development or tackling technological injustice, as well as to enable engineers to participate in correcting those structures 'that may need to be changed if engineering and technology are to contribute to human welfare' (Conlon and Zandvoort 2011, 226). These two frames can be seen as ideal types, reflecting different goals and approaches to the teaching of engineering ethics. They provide a useful analytical lens for understanding different approaches to the use of case studies. The main differences between the two educational models can thus be summarised as seen in Table 1.

A review of articles describing the application of case studies in engineering ethics education reveals that the instruction method has been preponderantly used within a microethical outlook, focused on describing individual dilemmas set in scenarios of crisis (Haws 2001). There is less 
Table 1. Models of engineering ethics education: Microethics vs Macroethics.

\begin{tabular}{|c|c|c|}
\hline FRAME & MICROETHICS & MACROETHICS \\
\hline $\begin{array}{l}\text { Themes and } \\
\text { Topics }\end{array}$ & $\begin{array}{l}\text { Professional codes } \\
\text { Ethical theories } \\
\text { Ethical heuristics }\end{array}$ & Social, cultural, economic and political dimension of engineering \\
\hline $\begin{array}{l}\text { Teaching } \\
\text { Methods }\end{array}$ & $\begin{array}{l}\text { Ethical dilemmas that allow for } \\
\text { win-win answers }\end{array}$ & $\begin{array}{l}\text { III structured learning environments } \\
\text { Ambiguous and complex scenarios }\end{array}$ \\
\hline Goals & $\begin{array}{l}\text { Refine moral reasoning } \\
\text { Develop moral character }\end{array}$ & $\begin{array}{l}\text { Broaden focus of ethics to include broader context of individual decisions } \\
\text { and societal obligations of the profession }\end{array}$ \\
\hline Responsibility & Individualistic & Collective and societal \\
\hline Agency & $\begin{array}{l}\text { Assumption of full agency of the } \\
\text { engineer }\end{array}$ & Dependent on enabling or constraining contextual factors \\
\hline Values & $\begin{array}{l}\text { External to the context of practice } \\
\text { Neutral stance }\end{array}$ & $\begin{array}{l}\text { Embedded in the context of practice } \\
\text { Commitment to a set of values }\end{array}$ \\
\hline
\end{tabular}

attention given to macroethical aspects such as public policy and the broader social mission of engineering (Colby and Sullivan 2008; Bielefeldt et al. 2016).

Several benefits of microethical case instruction have been highlighted, such as refining moral judgement, enhancing ethical will-power and familiarising students with professional standards of conduct (Davis 1997; 1999). Nevertheless, while students do show 'an ability to recognize obvious black and white ethical dilemmas', they fail to do so for 'more subtle but possibly more serious dilemmas' (Shuman et al. 2004, 11). In recent years, case instruction has attracted criticism pointing to its weakness in capturing the dynamics and complexity of the profession (Lynch and Kline 2000; Bucciarelli 2007). Some of the method's minuses that have been set forth point to its weakness on both ontological and epistemological grounds (Martin, Conlon, and Bowe 2018).

Ontology is a branch of metaphysics that explores questions about the nature of existing entities and artefacts, their structure and relationship, as well as questions about emergence and persistence, processes and events (Simons 2011; 2013). If we are to consider the ontology of engineering, the literature identifies three ways in which the use of case studies in the teaching of engineering ethics fails to capture the characteristics of engineering, related to the nature of (i) the artefacts produced, (ii) engineering practice and (iii) the professional environment. Furthermore, there is also an epistemological deficit of the microethical use of case studies, which rests on the assumption that (iv) engineering knowledge is fully explicit and readily available by consulting codes and theory, thus neglecting its strong tacit and practice based character.

\subsection{Ontological deficits of microethical case instruction}

The microethical use of case studies in engineering ethics fails to capture the ontological characteristics of engineering on three counts:

A first objection from an ontological perspective is that microethical approaches to case studies seem to elude the nature of engineering artefacts. These are not mere products whose creation is restricted to the application of scientific principles, but they also comprise a certain social dynamic, power relationships or can have political effects (Winner 1986; Bijker 1995; Feenberg 1999). Marzano (1993), the now retired chief design officer of Electrolux, stated that 'design is a political act', such that 'every time we design a product we are making a statement about the direction the world will move in'. This seems to be the case with the bridges of Long Island towards Jones Beach designed by Moses, whose low height did not allow busses to pass under them. At the time, public transport was the preponderant means of transportation of the poor black and immigrant population. Automobile owning white people of 'upper' and 'comfortable middle' classes, as Moses called them, would be free to use the parkways for recreation and commuting, while people of black and Puerto Rican origin, who typically used public transit, were kept off the roads because the twelve-foot tall buses could not get through the overpasses (Caro 1974). 
As Winner (1986) has argued, the bridges of Long Island display one's view about race or social class, inasmuch as they display technological expertise. Bijker (1995) further elaborates on how technical artifacts are important in the constitution of power. The fluorescent lamp, which now seems an unproblematic everyday engineering artefact, is in fact the outcome of a complex economic power play in which General Electric, the electric utilities, the U.S. government and consumers all played a role, paving way to a major change of the manufacturing scene in the United States.

Engineering artefacts can incorporate dominant cultural stereotypes or the designer's biases, thus excluding the needs or characteristics of different categories of users. One such example are early voice-recognition technologies, which failed to recognise the voice of female users due to its higher pitch (Bath 2009). When looking at how algorithms discriminate against people of colour, Umoja Noble (2018) notices a systematic algorithmic culture of oppression. This bias goes beyond search engines such as Google or Yelp, affecting also electoral politics and financial markets (Pasquale 2014; 2015).

In terms of coverage, popular scenarios employed by case studies focus on presenting disasters such as the Challenger shuttle explosion, nuclear accidents, plane crash or building collapses, as well as more mundane situations encountered by engineers, such as conflict of interest or receiving gifts (Haws 2001, 226; Herkert 2005, 306-7; Freyne and Hale 2009, 8; Harris, Pritchard, and Rabins $2009,12-3)$. There is a 'tendency [...] to have only bad news cases, cases in which some bad outcome occurs because of poor choices' (Huff and Frey 2005, 401). This type of microethical 'bad news' cases are formulated according to a binary scenario focused on disaster and prevention. Thus, concerns about societal welfare are often reduced to 'situations of extreme crisis (such as being ordered to design an unsafe structure),' narrowing a potentially broad concept to microethical concerns about health and safety (Little, Barney, and Hink 2008, 216). Having their ultimate focus on health and safety rendered through the use of disaster scenarios, microethical case studies neglect the political or social beliefs that govern the creation of engineering artefacts and the manner in which technology mediates human activity or shapes power structures. In the words of Little, Barney, and Hink (2008, 325), micro-focused cases offer 'precious little in terms of how engineering decisions may either liberate publics or reinforce power relations over them'.

Second, as Beder $(1999,15)$ points out, the practice of engineering is not solely an application of technical skills, but 'a social process involving interaction between the design team, the client and others'. This claim is supported by Campbell, Roth, and Jornet's (2019) study which reveals the social and collaborative nature of decision-making in design. Bucciarelli (2008) talks about these two dimensions in terms of the distinction between an object world, that engineering pertains to through its technical dimension, and a social world, constituted through exchange and interaction of different subjectivities, marked by openness and flexibility. If the first is value neutral, rigid and objective, the second is rich in values and value judgements. But too often it is the object world that comes to the forefront when rendering the features of the engineering profession in educational objectives and practices.

Microethical case studies present an individualistic perspective that asks an agent to make a decision (Kline 2010) - postpone the Challenger launch, design weapons of mass destruction neglecting what Devon and Van de Poel (2004) call 'the social arrangements for making decisions'. This approach is 'relatively unconcerned with ethical problems of multiagent situations, ignoring the influence of social factors' (Tai 2013, 582). Nevertheless, there are different subjectivities involved in engineering practice, each with their own values, backgrounds and goals, which come to shape the solution chosen, the artefact created or even the meaning of the values in use. In this regards, Lynch and Kline (2000, 198-9) note that 'moral choices are made continuously within a stream of ongoing practice, while a variety of different agents with varied interests and experiences shape decisionmaking'. It is to this subjective process that comes to influence decision-making in engineering professional settings that Vaughan (1996) points in her analysis of the Challenger disaster. Here, Vaughan (1996) shows how incremental change over time in what was considered an acceptable risk within the organisational culture of NASA led to a 'normalization of deviance', which later contributed to 
the explosion of the Challenger shuttle. What happened was that the meaning and range of what was deemed 'safe' was altered through the continual interaction of multiple subjects and based on a history of previous successful launches that stretched the range of safety values. This paved way for the decision to launch the Challenger at a lower temperature than that of previous tests and launches, despite the fact that one component was susceptible to fail in cold conditions.

Third, microethical case instruction rests on the assumption that moral values are external to the context of practice, rather than embedded within a social or political climate, institutional practice or corporate culture. If we consider that making a moral choice in engineering means pursuing values such as social responsibility, safety and sustainability, and these values exist independently from the context of practice, then we are assuming that the individual engineer has full agency to pursue them. In this case, the engineer is regarded as having agency regardless of the characteristics of the structure s/he is part of. Winner $(1990,53-4)$ remarks that case studies used in engineering ethics education 'tend to focus upon relatively rare, narrowly bounded crises [...] while the contexts that underlie particular cases are never themselves called into question.' The focus of cases studies on disaster situations is seen by Verrax $(2017,77)$ to lead to a failure of engineering ethics education to take into account power structures.

Cases describing moral dilemmas are seen to allow for a win-win outcome, which given the external nature of moral values, can be solved through appeal to professional codes or ethical theories (Conlon 2015). In practice however, even if the engineer successfully identifies a course of action, s/he might still be unable to act upon her moral beliefs given the contextual constraints encountered (Davis 1991; Johnston, Lee, and Mc Gregor 1996). Microethical case studies stop at the local analysis of ethical dilemmas, but as Zandvoort, Van Hasselt, and Bonnet (2008) point out, many of the dilemmas faced by engineers cannot be

satisfactorily solved without amendments to the broader context, including the legal system, which determines, among other things, how organizations operate, and including the procedures for collective (political) decision making.

Moreover, the reliance of microethical case studies on professional codes as providing the right solution when faced with an ethical dilemma often does not suffice to make agents understand their moral responsibility or take a proactive stance in regards to ensuring that technological developments promote human welfare (van der Burg and van Gorp 2005; Little, Barney, and Hink 2008). In fact, it might mislead individuals into believing that as long as they adhere to the prescriptions of codes of ethics, they fulfil their duty towards society. Professional codes also fail to incorporate issues related to distributive justice, although as Hansson $(2017,51)$ stresses, 'technological resources are among the assets that can be justly or unjustly distributed among people'. Fitzpatrick $(2017,921)$ calls for engineering educators to make students aware that 'moving towards an environmentally sustainable paradigm is not just about technological solutions' and 'engage their students with the economic and social levers that have potential for moving humanity away from its current unsustainable path'. In his practice, Fitzpatrick relies on a macroethical case study proposed by Anderson to achieve this. Walling $(2015)$ and Moore $(2016,200)$ also argue that case studies need to be more than an 'exercise in analytical reasoning'. This implies 'confronting rather than ignoring the limited ethical agency engineers possess while working in collaborative settings.'

\subsection{Epistemological deficits of microethical case instruction}

In what follows, we turn our attention to epistemological concerns about what type of knowledge engineers use in their day-to-day practice and how these are captured in microethical case instruction.

Case studies presenting clear-cut individual dilemmas and situations of crisis that can impact the health and safety of the population typically point for their resolution to professional codes or moral theories (Little, Barney, and Hink 2008). Harris, Pritchard, and Rabins $(2009,99)$ call clear-cut ethical 
scenarios 'paradigmatic cases.' For example, paradigmatic microethical cases that present the perspective of an individual engineer faced with the situation of disclosing confidential information about the employer or accepting gifts and bribes find guidance in professional codes or national legislation (Ibid). In the case of disaster scenarios focused on preventive individual decisions, the resolution is found in rules that are usually stated in codes of ethics (Id., pp. 12-3).

Microethical cases presenting paradigmatic and disaster scenarios have important learning outcomes. They are also not inclusive of the entirety of microethical teaching approaches. The epistemologic weakness of an exclusive reliance on paradigmatic and disaster oriented microethical cases lies in their underlying assumption that engineering knowledge is fully explicit and readily available by considering existing theoretical provisions, regulations and guidelines for conduct (Shallcross 2013, p. e14). This is divergent with the way in which engineers report to conduct their practice, highlighting the significant role of tacit knowledge in the engineering profession (Gorman 2001; Gainsburg, Rodriguez-Lluesma, and Bailey 2010). Tacit knowledge is defined as 'an uncodifiable accumulation of skills that result from learning by doing,' thus eluding articulation (Reed and DeFillippi 1990, 89). Tacit knowledge is context-specific and can be passed on through socialisation, demonstration and imitation (Murphy, Stapleton, and Smith 2004). Conversely, explicit knowledge can be articulated, stored and explained.

Vincenti (1990) identifies six types of knowledge an engineer uses in her work, one of them being 'practical considerations' represented by 'information learnt mostly on the job and often possessed unconsciously, rather than in codified form'. Gorman (2001) also points out that according to interviews conducted with engineers, much of their expertise was based on tacit knowledge. A study conducted by Gainsburg, Rodriguez-Lluesma, and Bailey $(2010,209)$ revealed that two-thirds of the knowledge that structural engineers employ is practice generated, meaning it is 'context specific' and 'constructed in the course of everyday activities', with only a third representing 'historically established knowledge, retrieved from design manuals, building codes [...] and the bulk of what they learned in university courses'.

This sort of tacit knowledge, argue (Vermaas et al. 2011, 64), 'is often essential when it comes to deciding what risks to take or uncertainties to accept instead of carrying out further tests or developing more accurate models'. According to Gorman (2001), the tacit character of engineering expertise had a significant contribution to the Challenger disaster, as Boisjoly was unable to articulate his tacit knowledge during a final meeting where it was 'particularly hard to discuss tacit knowledge and experience-based intuitions'. Practical as well as ethical judgements rely on tacit knowledge. This is due both to the rapid pace and pressure under which engineering work is carried, and to the frequent lack of theories in tune with the continuous technological advancements in contemporary society that could recommend a line of action over the other (Vermaas et al. 2011). The reality of engineering practice is often ahead of prescriptions immortalised in codes or regulations that one can appeal to or consult, and in their absence, an engineer relies on her expertise gained through years of practice.

For Walling $(2015,1648)$, one limitation of engineering ethics case instruction is the focus on cognitive learning. According to her, the overreliance on case studies presenting disasters and ethical dilemmas may 'fail to foster students' moral imagination and sensitivity' (Id., p. 1646). Thus the skills instilled by microethical instruction are analytical rather than social, when in fact 'it is through the social dimension of the world that engineers engage as professionals' (Id., pp. 1647-8). Microethical case studies rendering scenarios which present disastrous outcomes or that take place in situations of crisis, based on concrete and certain data, end up resembling well-structured textbook problems (Latcha and Jordan 1996; Shallcross 2013). The case instruction method as originally designed differs from deductive interventions that have a clear-cut answer and a predetermined reasoning procedure leading up to it, yet a microethical approach allows case studies to be framed in a deductive format. In microethical instruction, the ill-structured function of case study pedagogy faces the risk of diluting into a well-structured approach to situations an engineering student might face as a professional. Yet 'instrumental, rational analysis never suffices in practice. 
Decision-making in engineering is a multi-factored affair and not all factors can be quantified', points out Bucciarelli (2008), as 'there is something more to doing engineering and dealing with ethical issues than finding answers to well posed problems'. That something more is the context in which engineering practice is embedded. Moriarty $(2001,32)$ emphasises the importance of this world of context, noting that

engineers typically take context as an add-on, often as a feature we are forced to address. The social context of engineering, for example, is often reduced to strategies for compliance with FCC or EPA regulations. Context is marginalized and seldom given voice by contemporary engineering practice. But, context is world, and engineering is inherently and fundamentally an in-the-world enterprise.

The ontological and epistemic deficiencies of paradigmatic and disaster oriented microethical cases identified overlap with a loss of important features of case pedagogy, purporting to their verisimilitude, multidimensional perspective, rich context, interactivity, ambiguity, implicitness and inductive character. A microethical approach to case studies can neglect their ill-structured function and the characteristics of the method. This leads to the need for developing alternative approaches to case instruction that would fully preserve the method's traits. Case studies used in the teaching of engineering ethics thus need to make students aware that: (i) the artefacts created incorporate also social and political values, (ii) the decision and design process of creating an artefact is also a social process, (iii) even if identifying the moral thing to do is a necessary first step for being a socially responsible engineer, acting upon it depends on wider structural factors, and (iv) engineering practice often includes ambiguous problems that do not lead to an ideal solution.

\section{Role-play in case study instruction}

Given the deficiencies of the traditional use of case studies in engineering ethics education identified in the previous section, we suggest that role-playing is one way to achieve the desired complexity of the case method while also rendering its characteristics. This implies introducing and assigning roles of various agents when presenting engineering students with case studies. (Lynch and Kline 2000, 199). There are several benefits brought by integrating role-play in a case study, as noted by those who employed this method of teaching engineering ethics.

Role-playing case studies widens the scope of the approach to a macroethical outlook that encourages engineering students to act responsibly, by designing value driven artefacts and solutions (Gorman, Mehalik and Werhane 2000; 2001), changing the policy structure engineers are part of as to enable agency (Doorn and Kroesen 2013) or navigating through constricting institutional dynamics (Kroesen and Van der Zwaag 2010). Gorman, Mehalik and Werhane (2000) and Gorman (2001) for example, developed at Virginia Tech several case studies based on the design of the new environmentally friendly fabric Climatex Lifecycle to which different active agents with different expertise contributed. At the core of the scenario was the goal of encouraging engineering students to be 'active moral agents who are capable of getting distance from our roles and behaving differently, in a way that promotes sustainable engineering. The scenario highlights the importance of 'articulating the moral framework' for a new compostable fabric design which can be turned to mulch after its disposal, promoting the value of 'waste equals food' (Gorman 2001, p. 24). The role-play component of the case study illustrates an active approach to designing environmental solutions, which would not have been possible without the initiative and cooperation of several agents with different expertise. Another macroethical use of case studies through role-play was put in practice by Doorn and Kroesen (2013). Their scenario focuses on an institutional framework that would enhance engineers' agency, such that students learn that 'not only individual decisions may be right or wrong, but that the very framework within which a decision is to be taken may be more or less conducive to doing the right thing' (Id., p. 1525). In the course of the exercise, students are familiarised with the different meanings and views employed in the scenario by the different stakeholders involved. A focus on the repressing force of social and political structures is found in Wilson's 
(2013) role-play of the Chernobyl nuclear disaster. By assigning students to one of the three factions The Soviet State represented by the Ministry of Atomic Power Stations, the State Committee for Safety in the Atomic Power Industry and the highest levels of the Soviet bureaucracy, the management of the nuclear plant and the engineering crew of the reactor - engineering students explore ethical issues in a wider context 'where personal well-being quite often ran up against professional responsibility in a political system that could often be quite brutal and unforgiving' (Wilson 2013, 636).

An additional benefit of role-playing macroethical scenarios is that it encourages students to take an active and sometimes creative stance for the design of an engineering artefact or the resolution of a situation (Gorman 2001; Doorn and Kroesen 2013). Role-playing also familiarises students with the different subjectivities involved in the design and creation of an engineering artefact or decision process, each bringing different backgrounds, problem conceptualisation and desired outcomes (Lloyd and van de Poel 2008; Loui 2009; Lewis, Van Hout, and HuangSaad 2010). Kang and Lundeberg $(2010,1134)$ note that a further advantage of realistic simulations along with role-playing 'situated in social networks' is that they 'provide the space for developing identities in practice'. Costello $(2017,648)$ also supports the beneficial aspects of simulated roleplay in helping students come to the realisation of what it means to 'become an engineer'. Furthermore, Hamzeh et al. (2017) observe that realistic simulations that feature different agents help students learn how decision-making affects various stakeholders and how to deal with incomplete information.

Thus, role-play can be used for developing macroethical case studies that shape the identity of what it means to be a socially responsible engineer, within a scenario that takes into account the complexity and the social dimension of the engineering profession.

\section{Proposal for redesigning the case study 'Cutting Roadside Trees'}

For the purpose of introducing students to the social dimension of engineering, we redesigned the case study 'Cutting Roadside Trees' as to include a contextual description of three polarising agents and assigned one of these three roles to first year engineering students. The aim of the redesigned case study is to contribute to an enhanced student understanding of the social dimension of engineering, namely the collaborative nature of engineering decision-making and the way in which different subjectivities can affect it. After presenting the theoretical underpinning of the intervention, we move on to describe the exercise itself.

\subsection{Theoretical underpinnings}

The pedagogical exercise is informed by a macroethical outlook driven by the ideal of enabling engineers to change the economic and social context in which they work as to promote the development of sustainable and safe solutions. A prerequisite for achieving this is to increase students' awareness about the constraining or enabling factors present in the workplace, the inherent imbalance of power and institutional dynamics, as well as the way in which different subjectivities interact and shape the decision-making process in the workplace.

As such, by familiarising engineering students with the mutable social arrangements involved in decision-making, a new conception of engineering ethics education is put forward that focuses on the contrast between ideal and actual norms and structures that characterise group processes and social institutions. A major gain of macroethical case studies is thus the switch from a portrayal of 'relatively powerless individuals to the actual processes of decision-making in technology, thereby making engineering ethics more relevant than it has been' (Devon 1999, 88). Macroethical case studies can help empower students to build their professional identity as socially responsible engineers and change actual engineering norms and structures for the better (Conlon and Zandvoort 2011). 


\subsection{Description of the redesigned cutting roadside trees case study}

At Technological University Dublin, we have put in practice for a first year module of Engineering Professional Practice a contextualisation of the case study Cutting Road Side Trees. This module is part of the General First Year programme which is taken by all students enrolled in a four year professional engineering degree. As part of this module, students complete group based projects focused on the issue of climate change for the full duration of the semester. There are approximately 140 students in the programme each year who are split into five divisions of approximately 30 students. In turn and for the purposes of this module these students are randomly placed in groups of five.

Pritchard's case had been used for a number of years in this module as a mechanism for getting students to interact with each other, become familiar with other members of their group and reflect on perceived difficulties they might have in working together. When discussing the case one, a member of the group is asked to be an observer and comment on the interaction in the group by answering questions such as Did everyone participate? Did one person influence the solution more than others? The observers' comments most often suggested that everyone had a say and that there were no issues related to power dynamics within the groups. This seemed to the instructors not to reflect reality. The observers' comments were seen to arise from the reluctance of first year students to criticise each other by suggesting their colleagues were either too dominant or too passive and unengaged. They needed some other way to reflect on the role of power within group scenarios. This provided further motivation for redesigning the exercise.

Thus, to the scenario designed by Pritchard (1992), we added a contextual description for the three main characters mentioned in the case study, which highlighted their professional experience and status within the organisation and community, their values and feared outcome, followed by a set of questions related to the scenario and how the group reached a decision. The contextualised case study given to students can be seen in Box 1 . The redesigned case study has been enacted two times since 2017, and for the purpose of this article we will be referring to the data collected in the academic year 2017-18. For the pilot role-playing exercise put in practice in the academic year 2016-17 (Martin, Conlon, and Bowe 2018) we noticed some deficiencies in regards to how the questions were formulated, such that for the second enactment of the exercise in 2017-18 we wanted to refine the questions as to delve deeper into the role played in the final decision of a perceived difference in power between roles according to students, as well as students' perception about the process of dealing with divergent preferred solutions. We acknowledge the importance of a continual refinement of questions to be asked of students

\section{Box 1. The contextualised Cutting Road Side Trees case study.}

'Kevin Clearing is the engineer for the Verdant County Road Commission (VCRC). VCRC has primary responsibility for maintaining the safety of county roads. Verdant County's population has increased by $30 \%$ in the past 10 years. This has resulted in increased traffic flow on many secondary roads in the area. Forest Drive, still a two lane road, has more than doubled its traffic flow during this period. It is now one of the main arteries leading into Verdant City, an industrial and commercial center of more than 60,000 people.

For each of the past 7 years at least 10 persons have suffered a fatal automobile accident by crashing into trees closely aligned along a 3 mile stretch of Forest Drive. Many other accidents have also occurred, causing serious injuries, wrecked cars, and damaged trees. Some of the trees are quite close to the pavement. Last year two law suits have been filed against the road commission for not maintaining sufficient road safety along this 3 three mile stretch. Both were dismissed because the drivers were going well in excess of the $45 \mathrm{mph}$ speed limit.

Members of VCRC have been pressing Kevin Clearing to come up with a solution to the traffic problem on Forest Drive. They are concerned about safety, as well as law suits that may someday go against VCRC. Clearing now has a plan - widen the road. Unfortunately, this will require cutting down about 30 healthy, longstanding trees along the road.

Clearing's plan is accepted by VCRC and announced to the public. Immediately a citizen environmental group forms and registers a protest. Tom Richards, spokesperson for the group, complains, 'These accidents are the fault of careless drivers. Cutting down trees to protect drivers from their own carelessness symbolises the destruction of our natural environment for the sake of human 'progress.' It's time to turn things around. Sue the drivers if they don't drive sensibly. Let's preserve the natural beauty and ecological integrity around us while we can.' 
Many letters on both sides of the issue appear in the Verdant Press, the issue is heatedly discussed on local TV, and Tom Richards presents VCRC with a petition to save the trees signed by 150 local citizens.' (Pritchard 1992)

Correspondingly, the three character descriptions added in our intervention are:

-The young engineer

You are Kevin Clearing, an engineer who graduated 6 years ago and is now working as an engineer at the Verdant County Road Commission. You enjoy your work and hope to get in the next 6 months a promotion as engineering manager, knowing that your professional trajectory within VCRC depends on the board and how satisfied they are by your decisions. In your work you value practical solutions and you take pride in considering sustainability in your decisions.

-The top manager

You have worked for VCRC for more than 30 years. Back in the days Verdant was a small community with light traffic, which saw one lethal car accident every few years. The current traffic brings new challenges for your line of work and you fear that losing a lawsuit would have disastrous consequences for the public image of VCRC and for an already strained budget. You value decisions that protect the image of VCRC and are cost effective.

-The influential environmentalist

You are Tom Richards, and have been living in the Verdant County since you were born, 60 years ago. You appreciate its natural scenery, and consider that the forest lining up besides each side of the road, home to so many wild species, is an invaluable part of the city Verdant. The recent urban developments have already led to some of the county's green areas get torn down to make room for industrial buildings, and now you fear that the new deforestation plans of VCRC will continue such a trend. The group you represent aims to protect the natural habitat that makes Verdant County unique. You value nature and want your grandchildren to enjoy the same landscape and quality of air that you have benefitted from.

as a complement to the role-playing of the scenario, and see this very much as work in progress requiring further refinement. Doorn and Kroesen (2013) note that role-playing by itself is not sufficient in raising student awareness about wider structural issues pertaining to the engineering profession. Therefore they require opportunities and mechanisms for reflecting on the role-playing activity.

The exercise was applied to 80 first year students during workshops for the Engineering Professional Practice module, during the spring semester of the academic year 2017-18. The students were in the workshops facilitated by two of the authors. In one set of workshops the exercise was conducted in the traditional way, while in the other set the new contextualised case study was used. The exercise was conducted as follows:

1. A control section consisting of 42 students, all of them consenting to participate in the research. They were split into eleven groups of 3-5 students, ${ }^{2}$ and given the case study Cutting Roadside Trees as designed by Pritchard (1992). As had been done in previous years, students from the control section were asked to assume the individualist perspective of the engineer in the scenario Kevin Clearing - and discuss how this character should proceed. In the pre-discussion phase, they were asked to answer by themselves two questions: what is the main problem that Kevin has to solve and what is the best solution for it. They then had to discuss the two questions with their group and arrive at agreement on the answer to the two questions available in the Question set for the control section in Box 2. Observers, as mentioned above, were asked to observe the groups' interactions and complete a short questionnaire.

2. The experimental section consists of another 42 students. Among these, 38 students consented to take part in the research. The students from the experimental section were given the redesigned scenario in Box 1, to which we added a contextual description for the three main characters of the case study, highlighting their professional experience and status within the organisation and community, their values and feared outcome. The students were split into twelve groups of 3-4 students. ${ }^{3}$ 


\section{Box 2. Question sets accompanying the intervention.}

\section{QUESTION SET - CONTROL SECTION}

After reading the scenario, discuss how Kevin Clearing should proceed at this point.

Think about the following question for $5 \mathrm{~min}$ by yourself:

What is the main problem that Kevin has to solve?

What is the best solution?

Discuss the two questions in your groups and arrive at an agreement on the answer to the two questions. Pick one member of your group to report back.

\section{QUESTION SET - EXPERIMENTAL SECTION}

After reading the scenario, please answer individually the following questions:

Q1) What is the main problem faced by Verdant County?

Q2) What do you (Kevin Clearing/ VCRC/ Tom Richards, depending on the role) consider to be the best solution for this problem?

Q3) Why do you (Kevin Clearing/ VCRC/ Tom Richards, depending on the role) think this is the best solution?

Q4) What do you (Kevin Clearing/ VCRC/ Tom Richards, depending on the role) think are the main barriers for achieving this solution?

After answering these questions, discuss the scenario with your group by adopting the stance of the character you represent and agree on a solution/line of action $(20 \mathrm{~min})$. Then answer the following questions $(10 \mathrm{~min})$ :

Q5) What solution was reached following the discussion?

Q6) What criteria or values have been considered to reach this solution?

Q7) Was the solution agreed by all or did one person have more influence? Why do you think this happened?

Q8) Do you personally agree with the solution reached? Why/Why not?

Q9) Any comments on how your group approached the case?

Each student of the twelve groups was given a role, that of a young engineer, a top manager or an influential environmentalist as described in Box 1, such that each group contained at least one student for each role. There were 12 students who received the role of the young engineer, 13 students who received the role of the top manager and 17 students who received the influential environmentalist role. Among these, 10 students who received the role of the young engineer, 11 students who received the role of the top manager and 17 students who received the influential environmentalist role gave their approval for their answers to the survey to be used in the present research study. The description for the roles of the young engineer Kevin Clearing, the influential environmentalist Tom Richards and the top manager of the public body VCRC is provided in Box 1.

In the pre-discussion phase, the exercise required students from the experimental section to read the scenario and answer in writing by themselves, in light of the role they received, questions about Q1) the main problem faced by Verdant County, Q2) What does their character consider to be the best solution for this problem, Q3) Why their character thinks this is the best solution and Q4) What does their character think are the main barriers for achieving this solution? Afterwards, they were asked to discuss in their group and Q5) propose a solution to the dilemma informed by the contextual information provided and the discussion among themselves. Students were also required to answer questions about Q6) What criteria or values have been considered to reach this joint solution, Q7) Whether the solution was agreed by all or did one person have more influence and Why did they think this happened, Q8) whether the student personally agreed with the solution reached and why was that the case and finally Q9) the student could write her/his comments on how the group approached the case. 
The answers were collected and represent the data on which this paper draws. The focus is on the solutions offered by the different kinds of groups, finding that more diverse solutions were offered by the experimental section. The paper also examines whether the use of the role-play scenario contributed to an understanding of the social dynamics of engineering decision-making.

\section{The intervention based on role-playing the redesign of the case study cutting Roadside trees}

The aim of our intervention is to familiarise students with the social dimension of engineering. The research question driving our study is whether role-playing the case study Cutting Roadside Trees based on an extended description of characters contributes to an awareness of the collaborative nature of engineering decision-making and the way in which different subjectivities can affect it. We proceed now by describing the methodology and methods used, in order to describe the findings of our study.

\subsection{Methodology and research methods}

The methodology of action research stands at the basis of our study. The main characteristic of action research is that theory and practice are intertwined, with the goal of changing 'an immediate problematic situation' referring to the current practice of the researcher (Avison et al. 1999). McNiff, Lomax, and Whitehead $(2010,5)$ note that 'the action aspect of action research is about improving practice, while the research aspect is about creating knowledge about practice'. Thus this methodology is particularly helpful in educational settings, where instructors can reflect on and improve their teaching practice. Action research is an iterative and cyclic process, which starts from observations encountered in practice, proceeds with a plan aimed at correcting the deficiencies previously identified, followed up by its testing and a reflective analysis of how the findings of the intervention can pave the way for implementing a change in practice (Tripp 2005). Our approach followed the same cyclical format, starting from observations grounded in the application of the case study Cutting Roadside Trees for several years and the reluctance of students to identify power dynamic within groups leading to the joint resolution of the case study. One way to address this was by emphasising each of the three diverging characters described in the scenario and asking students to role-play them in their group.

The data presented here is based on the solutions offered firstly by individuals and then by groups, as requested in Box 2. The solutions were coded according to recurrent themes identified in them. Given the greater diversity of solutions offered by the experimental section, responses to the 'reflective' questions were analysed and again coded according to recurrent themes identified in them. While a set of questions was given to the observers in the control section, this data is not presented as in previous years it offered little insight into the group dynamics, indicating that all decisions were reached by consensus with everybody having an equal say.

\subsection{Findings}

The key findings reveal that in the contextualised scenario, students acknowledge the social dimension of the engineering profession. Experimental groups using the contextualised role-play scenario (i) provided more diverse solutions, (ii) indicated an awareness of the value laden nature of engineering solutions, and (iii) an awareness of the social dynamics in engineering decision-making, involving a need for compromise but also an acknowledgment of the power associated with different roles.

\subsubsection{More diverse solutions}

One of the questions addressed to both the control and experimental sections asked students to name their preferred solution, prior to discussing in groups and agreeing on a joint discussion. 
Table 2. Individual solutions to the Q: What do you consider to be the best solution for the problem? (number of mentions).

\begin{tabular}{|c|c|c|c|c|c|c|}
\hline $\begin{array}{l}\text { ANSWERS } \\
\text { RESPONDENTS }\end{array}$ & $\begin{array}{l}\text { Widen road } \\
\text { (cut trees) }\end{array}$ & $\begin{array}{l}\text { Changing drivers' behavior } \\
\text { (safety measures) }\end{array}$ & $\begin{array}{l}\text { Public } \\
\text { transport }\end{array}$ & Structural & Compromise & Research \\
\hline $\begin{array}{l}\text { Control section ( } 42 \\
\text { students) }\end{array}$ & 24 & 20 & 2 & 0 & 1 & 1 \\
\hline Young engineer (10) & 4 & 7 & 1 & 0 & 0 & 0 \\
\hline Top manager (11) & 3 & 7 & 0 & 0 & 1 & 0 \\
\hline $\begin{array}{l}\text { Influential } \\
\text { environmentalist (17) }\end{array}$ & 1 & 16 & 1 & 1 & 0 & 0 \\
\hline
\end{tabular}

The answers were then coded into six categories: solutions that mentioned expanding the road or cutting the trees were placed in one category. In another category we grouped answers mentioning saving the trees by changing the drivers' behaviour to diminish the number of accidents, through different methods such as imposing safety limits, introducing roadside barriers, additional road signs, traffic cameras and speedbumps, an increased police force, increased sanctions for speeding drivers such as higher fines or suing the drivers that are caught driving over the limit. A third category of answers mentioned as a solution to the dilemma was the compromise between the parties, without going into detail what that compromise amounts to in their opinion. A fourth category of answers refers to the introduction of public transport. A fifth category of answers mentions the need for additional research to be carried out on how the city and its population are affected before proceeding to the final solution. Finally, the sixth category identifies structural issues, such as stopping the rate of industrialisation of the region.

Table 2 shows the solutions to the scenario given in the pre-discussion stage, according to the six categories identified. We can see that a greater variety of solutions emerged from the groups who engaged in the role-playing scenario.

For the control section, when answering the question about the preferred solution, there were 48 solutions mentioned by the 42 respondents in this section, with $14 \%$ of the respondents giving multiple solutions. Over half of the respondents from the control section opted for a solution that is less favourable for the environment, mentioning expanding the road at the expense of cutting the trees. In the experimental section given the contextualised scenario, multiple solutions were mentioned by $12 \%$ of respondents who had an environmentalist role and by $20 \%$ of the respondents who had the role of the young engineer. Among the respondents from the experimental section, a solution that favoured expanding the road and cutting the trees was mentioned by $5 \%$ students who were given the environmentalist role, by $40 \%$ of students assigned the young engineer role and $27 \%$ assigned the top manager role. In all, only $21 \%$ proposed widening the road. However, as can be seen, there were significant differences between those adopting the different roles.

We can see there is a marked difference in the solution proposed between the control section and the environmentalist typology, with students assigned the roles of the young engineer and manager which were more likely than those with an environmental role to cut the trees. Still, among the students who received the contextualised scenario, the solution of cutting the trees did not outnumber solutions meant to enhance safety, as happened with the students from the control section.

According to Table 2, the role adopted by students seems to have informed the preferred approach. The students who were assigned different roles also chose multiple solutions in a higher percentage. Students assigned an environmental role recorded the highest number of mentions (84\%) for solutions targeted at enhancing safety through constructing speed barriers or implementing sanctions, which would thus avoid cutting trees. The difference in replies based on the different roles assigned seems to suggest that a contextualised scenario that assigns students different roles contributes to students' understanding that the perspective they adopt embeds certain values, which are in turn reflected in the solution they put forward.

Throughout the discussions we noticed a change in the solutions described by students assigned the roles of the young engineer and top manager. For the experimental section, the final solution was 
Table 3. Group solution for Q4: What solution was reached following the discussion? (number of mentions).

\section{ANSWERS}

Changing drivers' behavior (safety measures)

Cut the trees

Experimental section (12 groups)

Control section (11 groups)

12

6

reached after discussions in small groups comprised of the three different typologies, while for the control section the groups were comprised by respondents who were given the individualistic perspective of the young engineer. As such, as seen in Table 3, there was a significant diminishing of the number of proposals to cut the trees for the experimental sections that received the contextualised scenario.

Of the 12 groups from the experimental section, $8 \%$ decided to cut the trees, while also mentioning a form of compromise (such as 'cutting a lower number of trees than the one initially proposed') alongside measures for enhancing drivers' safety. There were eleven groups in the control section and $55 \%$ decided to cut the trees. Only $17 \%$ of the groups that opted for cutting the trees mentioned also a form of compromise such as 'replanting the trees elsewhere or cutting half the number of trees'.

\subsubsection{The need to compromise}

The answers of the groups who role-played the contextualised scenario seems to show some acknowledgment of the need to compromise and a greater consideration towards environmental concerns. This strengthens the idea that when students are exposed to scenarios presenting different actors, each with their own typology, that need to interact to reach a solution, the outcome reflects this difference. Students thus become more aware that engineering design and decision-making is also a social process.

The need for compromise was identified as a criteria for the final group decision in the answer given by some of the students in the experimental section to Question 6 'What were the values and criteria considered when deciding the solution to the scenario?' As seen in Table 4, 10\% of the respondents in the experimental section mentioned 'compromise' as a criteria they considered in their final decision.

Compromise was also mentioned in the responses to Question 8 as to why they personally agreed with the solution reached. $74 \%$ of the respondents from the experimental section detailed the reason why they agreed with the group decision, with $18 \%$ of those that chose to answer this question alluding to compromise by responding they agreed with the group solution because it 'seemed like the best way to reach the goal with everyone's concerns addressed,' 'benefits all sides,' 'suited everyone,' 'suits the need of all' or 'keeps both sides happy'. Over half of the respondents replied to Question 9 that asked for comments on how the group approached the case, putting an emphasis on compromise and agreement, as seen in Box 3. A 'heated debate' that culminated in compromise and agreement was mentioned in $20 \%$ of these comments, while $50 \%$ students opinionated that the final decision was the outcome of a discussion that explored all perspectives. The answers suggest that the respondents took into consideration different viewpoints when making the final decision, which shows that the exercise contributes to students' understanding that different subjectivities influence the decision-making process.

Table 4. Values and criteria influencing the solution to the scenario.

\begin{tabular}{|c|c|c|c|c|c|c|c|}
\hline $\begin{array}{l}\text { ANSWERS } \\
\text { RESPONDENTS }\end{array}$ & Environment & Safety & Social & Financial & $\begin{array}{l}\text { Public } \\
\text { Image }\end{array}$ & Compromise & $\begin{array}{c}\text { Soundness of } \\
\text { argument }\end{array}$ \\
\hline Young engineer (10) & 9 & 4 & 3 & 0 & 0 & 1 & 0 \\
\hline Top Manager (11) & 10 & 4 & 4 & 2 & 1 & 1 & 0 \\
\hline Influential environmentalist (17) & 14 & 7 & 4 & 0 & 0 & 2 & 1 \\
\hline
\end{tabular}




\section{Box 3. Answers to Q9) Any comments on how your group approached the case?}

Students given the environmentalist role responded (note that some students chose not to respond to this question):

- 'discussed the ideas from both perspectives. Argued counterpoints'

- 'took everyone views into account and everyone was heard'

- 'by sharing multiple ideas until we find the perfect one'

- 'by discussing'

- 'we discussed all aspects'

- 'heated debate followed by an agreement'

- 'debate'

- 'we all gave our opinions and reached the solution through discussion'

Students given the young engineer role responded (note that some students chose not to respond to this question):

- 'we considered all aspects'

- 'we worked very well as a team'

- 'civilized'

- 'majority agreed'

- 'I liked how we expressed ideas and solutions as environmentalists first then engineer, then manager so no influence to less powerful parties (researcher's note: this is in line with the advice given during one of the seminars that 'most powerful should speak last during meetings')

Students given the top manager role responded (note that some students chose not to respond to this question):

- 'heated debate followed by agreement'

- 'everyone had good ideas and worked well together'

- 'tried to keep all parties satisfied'

- 'by looking at different ideas'

- 'we all had the same values in mind which made it easy to agree on'

- 'I am happy with the approach and outcome'

- 'there was great debate in the discussion, we had a compromise, at the end we agreed'

One way in which different actors are seen to contribute and affect an engineering solution is suggested by the answer to the question about the values and criteria which contributed to the final decision that followed each discussion. Table 4 shows a wide spread of values, with numerous mentions each, revealing that there was no single value or perspective imprinted on the solution. The answers were again coded based on similarities, leading to six categories. We grouped answers mentioning the protection of the environment or the importance or saving the trees in the category named 'Environment'. The category headed 'Safety' mentioned the need to put human safety first, protect drivers and reduce accidents. Answers mentioning considering the values and the concerns of the community were marked under the category 'Social.' Under the category 'Financial - Public Image' we included answers about the strained local budget, saving money and avoiding lawsuits that would affect the public image. Answers mentioning coming to a compromise made up the category 'Compromise', while the answer mentioning that the main criteria for choosing a solution was which argument seemed most logical was placed in the category 'Soundness of argument.'

The students brought in a wide range of values in making their decision, taking into consideration environmental, social and financial reasons as well as the importance of public image and enhancing safety. The solution that resulted from the discussion can be seen as the outcome of the different values brought in by different actors. The students had to take into account different perspectives in their decision-making process that would lead to a joint solution. The results show that the role-playing scenario can convey to students awareness of the social values embedded in engineering artefacts and decisions, by enabling them to reflect on a solution to the scenario based on the characteristics and values of the role each received, with all of these values playing a role in the final group decision.

\subsubsection{Power}

When asked what they consider to be the barrier to achieving the desired solution in the pre-discussion stage, according to the description of their character, each of the three typologies identified 
Table 5. Identified barriers for solving the scenario (mentions).

\begin{tabular}{lcccccc}
\hline ANSWERS & & & & \multicolumn{2}{c}{$\begin{array}{c}\text { Lack of a perfect } \\
\text { solution }\end{array}$} \\
\hline RESPONDENTS & Environmentalist & Management & Community & Financial & Structural & 1 \\
Young engineer (10) & 4 & 3 & 2 & 1 & 0 & 5 \\
Top manager (11) & 2 & 0 & 3 & 1 & 0 & 1 \\
Influential environmentalist (17) & 0 & 9 & 5 & 3 & 2 & 1 \\
\hline
\end{tabular}

other actors involved in the process. As seen in Table 5, the most mentioned barrier by the young engineer and the environmentalist typologies is one of the other parties or the local community, with young engineers being the only role that named both other parties.

The young engineer's identification of both other parties as a barrier to their preferred individual solution seems to point to what they perceive to be the delicate position occupied by engineers on a low hierarchical level and the pressure faced of pleasing different and opposing sides. Students assigned top manager roles were more likely to identify as a barrier a decision-making factor such as 'the lack of a perfect solution'. We can also note that there is a lower concern with structural factors, such as 'management of traffic' or 'resources' and more on how different actors can affect the solution to the problem.

Students also showed some awareness of the existence of power dynamics in the workplace, as shown by comments for Question 9 about how the group approached the scenario (see Box 3). The power dynamics associated with the role assigned was mentioned as a factor that students took into account when discussing, as a group, their understanding of the solution - one student commented that the order in which they presented their preferred solution took into account the different power associated with different roles, and as such in their group they 'expressed ideas and solutions as environmentalists first, then engineer then manager so no influence to less powerful parties.' This might be a result of the instruction received during one of the seminars of the course dedicated to team work, which highlighted the importance of letting the person with the most authority speak last. An answer to Question 7 'Was the group solution agreed by all or did one person have more influence' also hints at the power associated with the management role in the final decision of the only group whose final decision included cutting the trees, the student commenting that s/ he does not agree with the final decision and one student in their group had more influence 'because (n.m. s/he) is a manager.'

According to the data collected, the answers of the students who were presented a contextualised scenario were diverse and complex, reflecting an awareness of how the interplay between agents with different goals and values influences decision-making in relation to the engineering process. By receiving a description of different actors involved in the design and decision-making process of the engineering profession, students showed some awareness of the importance of other actors and the need to engage with them in reaching a solution. This leads us to suggest that to better convey the social dimension of the engineering profession, case studies can benefit from including more contextual information that details the characteristics of the actors presented in the scenario and assigning students different agent roles.

\section{Limitations}

The first limitation of the study is related to the different sets of questions that the respondents in the control and experimental sections are required to answer. Given the way the exercise was constructed, juxtaposing the individual vs the socialised perspectives, the study cannot directly compare the control and experimental sections on all questions. The present study examines whether the use of the role-play scenario contributed to making the respondents aware of the social dynamics of engineering decision-making, analyses their understanding of the social dimension of engineering and explores whether it is an effective approach for expanding case studies 
beyond scenarios that are framed in individualistic terms. A difference is visible when the groups from both sections are asked to name the joint solution reached by their group, with a significant focus on measures meant to avoid the cutting of trees reported by the groups from the experimental section. The intervention is a work in progress and further refinement of the exercise is planned to allow both groups to reflect on the exercise in a similar way.

A second limitation is that the study did not collect demographic information about the respondents. The participants are also the students' of the researchers. The study received ethical approval, which required that the respondents be handed a consent form together with an information sheet. These documents stated that no identifying information of the respondents should be included in the answer sheet. This specification is meant to assure students of the confidential character of their responses and that the content of their responses or decision not to participate in the research will have no positive or negative impact on their grading for the module in which the intervention described in the current study is a component. Answer sheets were not collected separately. The answer sheets of each group were collected together in order to observe how each group approached the case study, as well as the final solution preferred by each group. Given that the student cohort is made of a varied mix of local and international students, of different racial backgrounds, as well as comprising both young and mature students, the identification of the respondents (in their capacity as students) by the researchers (in their capacity as lecturers) would have been unavoidable if demographic details had been included. We consider that the lack of demographic details does not have a negative impact on the main results of the study. The researchers were less focused on how different demographic categories of respondents address the scenario, as on how the respondents approach the group decision-making process in a scenario that asks them to adopt dissimilar positions and on how they understand the social aspect of engineering decision-making.

A third limitation concerns the male-centric nature of the three characters that the students are asked to role-play. In the description of the current study, the authors used the names from the original case study designed by Pritchard (1992). This aspect cannot be corrected at this point, but will be taken into consideration for future applications of the exercise. We acknowledge it is important to ensure that female engineering students feel represented in the pedagogical interventions they are exposed. We encourage those interested in applying the role-playing scenario in their teaching to make the necessary adjustments to the character's description to ensure a gender neutral representation. One way to achieve this is by employing non-gender specific names or by avoiding the inclusion of any names.

\section{Conclusion}

While this exercise is a work in progress and gathers data from a relatively small group of students at the early stages of the engineering studies, we believe that it manages to convey some key aspects related to the social dimension of the engineering profession, namely that engineering artefacts contain social values and that the process of design and decision-making are social processes. Our data based on the contextualised Cutting Roadside Trees exercise shows that role-playing has contributed to making students aware of the different values that need to be considered in engineering solutions and the way in which different agents come to affect the decision process.

The study brings a contribution to the limited empirical research investigating how cases should be taught in engineering ethics education (Yadav et al. 2007; Thiel et al. 2013; Davis and Yadav 2014). Many of the findings of this study are similar to those in the pilot study (Martin, Conlon, and Bowe 2018) and suggest that the work presented provides a fruitful avenue for educating students about the social context of engineering ethics issues, which should be developed further. Our findings are also consistent with Loui's $(2000 ; 2009)$ claim that students get to consider multiple perspectives when they participate in role-playing exercises and try to reach a satisfying compromise, thus gaining an awareness of the social dimension of engineering decision-making (Lloyd and van 
de Poel 2008). As Harkrider et al. $(2012,274)$ point out, the benefit of taking into consideration multiple perspectives and the consequences of their decision on others is that it enables students to make sense of complex and ill-defined situations and improves decision-making.

In light of the data collected, we argue that the use of role-play in engineering ethics education is an effective way to broaden the scope of case studies beyond an individualist approach towards a macro outlook, and by doing so to preserve the characteristics of the case method. Role-playing case studies can thus be a way to increase students' awareness of the complexity of the engineering profession.

\section{Notes}

1. When this research was conducted, the institution was known as Dublin Institute of Technology. In January 2019 it became an university and therefore its designation changed.

2. As in the case of the control section, students are split into groups of 5 for all group exercises and assignments throughout the module. Hence, for this roleplaying exercise, the groups were comprised of 3-5 students because some students were absent from the module on the day in question, such that no group was in full formation.

3. As in the case of the control section, students are split into groups of 5 for all group exercises and assignments throughout the module. Hence, for this roleplaying exercise, the groups were comprised of 3-4 students because some students were absent from the module on the day in question, such that no group was in full formation.

\section{Acknowledgment}

The authors are grateful to the anonymous reviewers for their work and the extended advice given for strengthening the previous versions of the manuscript to achieve the current form. We also want to thank the students who took part over the years in the exercise.

\section{Disclosure statement}

No potential conflict of interest was reported by the authors.

\section{Notes on contributors}

Diana Adela Martin is a PhD researcher at Technological University Dublin, College of Engineering and Built Environment, and assistant lecturer for seminars on Professional Practice. Her research examines the implementation of ethics education in Engineering programmes in Ireland and the evaluation of engineering ethics education by the national accreditation body. In 2008, she cofounded in Romania the NGO LEAP - Link Education and Practice, whose higher education projects were recognized in 2015 by the European Forum Alpbach as innovative in tackling inequality in higher education.

Eddie Conlon is a Lecturer in the School of Multidisciplinary Technology at the Technological University Dublin. He is generally interested in the sociology of work but in recent years has published work on engineering ethics and the integration of sustainability in engineering education. He teaches modules focused on engineering and society. $\mathrm{He}$ is the coordinator of a general entry programme for engineering technologists in the College of Engineering \& Built Environment at Technological University Dublin - City Campus.

Prof Brian Bowe is the Head of Academic Affairs and Assistant Registrar at Technological University Dublin - City Campus. Bowe holds an Honours Degree in Physics \& Mathematics, a PhD in Physics and a MA in Education. In 2000 he formed the Physics Education Research Group and in 2008 he established the Engineering Education Research Group. In September 2013, he merged these groups and created a new research group to encompass all STEM education research activities: CREATE. He has also facilitated over 300 education development workshops worldwide and consulted for numerous higher education institutes on topics such as problem-based learning, assessment, curriculum development, group learning and peer instruction. His education research interests include examining students' approaches to learning within group-based project-driven pedagogies, epistemological development, progression, conceptual understanding and pedagogical evaluations. 


\section{ORCID}

Diana-Adela Martin (D) http://orcid.org/0000-0002-9368-4100

\section{References}

Abaté, C. J. 2011. "Should Engineering Ethics Be Taught?" Science and Engineering Ethics 17 (3): 583-596.

Aldridge, M. D. 1994. "Professional Practice: A Topic for Engineering Research and Instruction." Journal of Engineering Education 83 (3): 231-223.

Avison, D. E., F. Lau, M. D. Myers, and P. A. Nielsen. 1999. "Action Research." Communications of the ACM 42 (1): $94-97$.

Bagdasarov, Z., C. E. Thiel, J. F. Johnson, S. Connelly, L. N. Harkrider, L. D. Devenport, and M. D. Mumford. 2013. “CaseBased Ethics Instruction: The Influence of Contextual and Individual Factors in Case Content on Ethical DecisionMaking." Science and Engineering Ethics 19: 1305-1322.

Barrows, H., and R. Tamblyn. 1980. Problem-Based Learning: An Approach to Medical Education. New York: Springer Publishing Company.

Barry, B. E., and M. W. Ohland. 2009. "Applied Ethics in the Engineering, Health, Business, and Law Professions: A Comparison." Journal of Engineering Education 98 (4): 377-388.

Barton, B. H. 2007. "A Tale of Two Case Methods." Tennessee Law Review 75 (3): 233-250.

Bath, C. 2009. "Searching for Methodology: Feminist Technology Design in Computer Science." GICT 2009 Proceedings. http://www.informatik.uni-bremen.de/soteg/gict2009/proceedings/GICT2009_Bath-geloescht.pdf.

Beder, S. 1999. "Beyond Technicalities: Expanding Engineering Thinking." Journal of Professional Issues in Engineering Education and Practice 125 (1): 12-18.

Bielefeldt, A. R., N. E. Canney, C. Swan, and D. Knight. 2016. "Efficacy of Macroethics Education in Engineering." 2016 ASEE Annual Conference and Exposition, New Orleans, Louisiana.

Bijker, W. E. 1995. Of Bicycles, Bakelites, and Bulbs: Toward a Theory of Sociotechnical Change. Cambridge, MA: The MIT Press.

Bonney, K. M. 2015. "Case Study Teaching Method Improves Student Performance and Perceptions of Learning Gains." Journal of Microbiology Education 16 (1): 21-28.

Bridgman, T., S. Cummings, and C. McLaughlin. 2016. "Restating the Case: How Revisiting the Development of the Case Method Can Help Us Think Differently About the Future of the Business School." Academy of Management Learning and Education 15 (4): 724-741.

Bucciarelli, L. 2007. Ethics and Engineering Education. http://dspace.mit.edu/bitstream/handle/1721.1/40284/ethics_20_ talk.pdf?sequence.

Bucciarelli, L. 2008. "Ethics and Engineering Education." European Journal of Engineering Education 33 (2): $141-149$.

Campbell, C., W.-M. Roth, and A. Jornet. 2019. "Collaborative Design Decision-Making as Social Process." European Journal of Engineering Education 44 (3): 294-311.

Caro, R. A. 1974. The Power Broker: Robert Moses and the Fall of New York. New York: Alfred A. Knopf.

Colby, A., and W. M. Sullivan. 2008. "Ethics Teaching in Undergraduate Engineering Education." Journal of Engineering Education 97 (3): 327-338.

Conlon, E. 2015. "Engineering Ethics: Ontology and Politics." Research in Engineering Education Symposium, Dublin, July 2015.

Conlon, E., and H. Zandvoort. 2011. "Broadening Ethics Teaching in Engineering: Beyond the Individualistic Approach." Science and Engineering Ethics 17 (2): 217-232.

Costello, G. J. 2017. "More than Just a Game: The Role of Simulation in the Teaching of Product Design and Entrepreneurship to Mechanical Engineering Students." European Journal of Engineering Education 42 (6): $644-652$.

Davis, M. 1991. "Thinking like an Engineer: The Place of a Code of Ethics in the Practice of a Profession." Philosophy and Public Affairs 20 (2): 150-167.

Davis, M. 1997. "Developing and Using Cases to Teach Practical Ethics." Teaching Philosophy 20 (4): 353-385.

Davis, M. 1999. Ethics and the University. Professional Ethics. London: Routledge.

Davis, C. 2005. "Developing, Implementing and Evaluating Case Studies in Materials Science." European Journal of Engineering Education 30 (1): 59-56.

Davis, C., and A. Yadav. 2014. "'Case Studies in Engineering"." In Cambridge Handbook of Engineering Education Research, edited by A. Johri, and B. M. Olds, 161-180. New York, NY: Cambridge University Press.

Devon, R. 1999. "Toward a Social Ethics of Engineering: The Norms of Engagement." Journal of Engineering Education 88: 87-92.

Devon, R., and I. Van de Poel. 2004. "Design Ethics: The Social Ethics Paradigm." International Journal of Engineering Education 20 (3): 461-469.

Doorn, N., and J. O. Kroesen. 2013. "Using and Developing Role Plays in Teaching Aimed at Preparing for Social Responsibility." Science and Engineering Ethics 19: 1513-1527.

Feenberg, A. 1999. Questioning Technology. London: Routledge. 
Fitzpatrick, J. J. 2017. "Does Engineering Education Need to Engage More with the Economic and Social Aspects of Sustainability?" European Journal of Engineering Education 42 (6): 916-926.

Freyne, S., and M. Hale. 2009. "A Preliminary Survey of Engineering Ethics Courses Nationwide." Paper presented at 2009 Annual Conference \& Exposition, Austin, Texas.

Fuchs, H. O. 1974. "On Kindling Flames with Cases." Engineering Education 64 (6): 412-415.

Gainsburg, J., C. Rodriguez-Lluesma, and D. E. Bailey. 2010. "A "Knowledge Profile" of an Engineering Occupation: Temporal Patterns in the Use of Engineering Knowledge." Engineering Studies 2 (3): 197-219.

Garvin, D. A. 2003. "Making the Case: Professional Education for the World of Practice." Harvard Magazine 106 (1): $56-65$. Gorman, M. 2001. "Turning Students into Ethical Professionals." IEEE Technology and Society Winter 2001-02: 21-27.

Gorman, M. E., M. M. Mehalik, and P. H. Werhane. 2000. Ethical and Environmental Challenges to Engineering. Upper Saddle River, N.J.: Prentice Hall.

Hamzeh, F., C. Theokaris, C. Rouhana, and Y. Abbas. 2017. "Application of Hands-On Simulation Games to Improve Classroom Experience." European Journal of Engineering Education 42 (5): 471-481.

Hansson, S. O. 2017. "Technology and Distributive Justice." In The Ethics of Technology: Methods and Approaches, edited by S. O. Hansson, 51-66. London: Rowman \& Littlefield International Ltd.

Harkrider, L. N., C. E. Thiel, Z. Bagdasarov, M. D. Mumford, J. F. Johnson, S. Connelly, and L. D. Devenport. 2012. "Improving Case-Based Ethics Training with Codes of Conduct and Forecasting Content." Ethics \& Behavior 22 (4): 258-280.

Harris, C. E., M. S. Pritchard, and M. J. Rabins. 2009. Engineering Ethics: Concepts and Cases. 4th ed. Belmont, Calif.: Wadsworth.

Haws, D. R. 2001. "Ethics Instruction in Engineering Education: A (Mini) Meta-Analysis." Journal of Engineering Education 90 (2): 223-229.

Herkert, J. R. 2000. "Engineering Education in the USA: Content, Pedagogy and Curriculum." European Journal of Engineering Education 25 (4): 303-313.

Herkert, J. R. 2005. "Ways of Thinking about and Teaching Ethical Problem Solving: Microethics and Macroethics in Engineering." Science and Engineering Ethics 11 (3): 373-385.

Herreid, C. F. 1994. "Case Studies in Science: A Novel Method for Science Education." Journal of College Science Teaching 23 (4): 221-229.

Hess, J., and G. Fore. 2018. "A Systematic Literature Review of US Engineering Ethics Interventions." Science and Engineering Ethics 24 (2): 551-583.

Huff, C., and W. Frey. 2005. "Moral Pedagogy and Practical Ethics." Science and Engineering Ethics 11 (3): 389-408.

Johnston, S. F., A. Lee, and H. Mc Gregor. 1996. "Engineering as Captive Discourse." Society for Philosophy and Technology Quarterly Electronic Journal 1 (3): 128-136.

Jonassen, D. H. 1997. "Instructional Design Models for Well-Structured and III-Structured Problem-Solving Learning Outcomes." Educational Technology, Research and Development 45 (1): 65-94.

Jonassen, D. H. 1999. "Designing Constructivist Learning Environments." In Instructional-design Theories and Models: $A$ New Paradigm of Instructional Theory, Vol. Il, edited by Charles M Reigeluth, 215-239. Mahwah, NJ: Lawrence Erlbaum.

Kang, H., and M. A. Lundeberg. 2010. "Participation in Science Practices While Working in a Multimedia Case-Based Environment." Journal of Research in Science Teaching 47: 1116-1136.

Kim, S., W. Phillips, L. Pinsky, D. Brock, K. Phillips, and J. Keary-Thomas. 2006. "A Conceptual Framework for Developing Teaching Cases: A Review and Synthesis of the Literature Across Disciplines." Medical Education 40: 867-876.

King, P. M., and K. S. Kitchener. 1994. Developing Reflective Judgment: Understanding and Promoting Intellectual Growth and Critical Thinking in Adolescents and Adults. San Francisco: Jossey-Bass.

Kitchener, K. S. 1983. "Cognition, Metacognition, and Epistemic Cognition: A Three-Level Model of Cognitive Processing." Human Development 26 (4): 222-232.

Kline, R. 2010. "Engineering Case Studies: Bridging Micro and Macro Ethics." IEEE Technology and Society Magazine 29 (4): 16-19.

Kroesen, J. O., and S. Van der Zwaag. 2010. Teaching Ethics to Engineering Students: From Clean Concepts to Dirty Tricks. The Impact of Practical Circumstances and Personal Relationships on Ethical Decision-Making." In Philosophy and Engineering, edited by I. R. Van de Poel, and D. E. Goldberg, 227-237. Dordrecht: Springer.

Latcha, M., and W. Jordan. 1996. "To Ship or Not to Ship: An Engineering Ethics Case Atudy," Technology-Based ReEngineering Engineering Education Proceedings of Frontiers in Education FIE'96 26th Annual Conference, Salt Lake City, UT, USA, 3:1159-1163.

Lewis, S., W. Van Hout, and A. Huang-Saad. 2010. “Teaching Biomedical Engineering Ethics: A Case Based Approach." 2010 IEEE Frontiers in Education Conference (FIE), Washington, DC: S3E-1-S3E-5.

Little, P., D. Barney, and R. Hink. 2008. "Living Up to the Code: Engineering as Political Judgment." International Journal of Engineering Education 24 (2): 314-327.

Lloyd, P., and I. van de Poel. 2008. "Designing Games to Teach Ethics." Science and Engineering Ethics 14 (3): $433-447$.

Loui, M. C. 2000. "Fieldwork and Cooperative Learning in Professional Ethics." Teaching Philosophy 23 (2): 139-156.

Loui, M. C. 2009. "What Can Students Learn in an Extended Role-Play Simulation on Technology and Society?" Bulletin of Science, Technology \& Society 29 (1): 37-47. 
Lundeberg, M. A. 2008. Case Pedagogy in Undergraduate STEM: Research We Have; Research We Need. Paper commissioned by the Board on Science Education, National Academy of Sciences.

Lynch, W., and R. Kline. 2000. "Engineering Practice and Engineering Ethics." Science Technology Human Values 25 (2): 195-225.

Martin, D. A., E. Conlon, and B. Bowe. 2018. "A Constructivist Approach to the Use of Case Studies in Teaching Engineering Ethics." In Teaching and Learning in a Digital World. ICL 2017. Advances in Intelligent Systems and Computing, vol 715, edited by M. Auer, D. Guralnick, and I. Simonics, 193-201. Cham: Springer.

Marzano, S. 1993. "Chocolate for Breakfast." Paper presented at Design Renaissance, International Design Congress, Glasgow.

McNiff, J., P. Lomax, and J. Whitehead. 2010. You and Your Action Research Project (2nd ed.). London: Routledge Falmer. Merseth, K. K. 1990. "Case Studies and Teacher Education." Teacher Education Quarterly 17 (1): 53-62.

Moore, K. 2016. "Ethics and Ingenuity: Creative Engagements of Ethical Dilemmas in the Engineering Writing Classroom." In Creative Ways of Knowing in Engineering, edited by D. Bairaktarova and M. Eodice, 197-218. Berlin: Springer.

Moriarty, G. 2001. "Three Kinds of Ethics for Three Kinds of Engineering." IEEE Technology and Society Magazine 20 (3): 31-38.

Murphy, F., L. Stapleton, and D. Smith. 2004. "Tacit Knowledge And Human Centred Systems: The Key To Managing The Social Impact Of Technology." International Multitrack Conference of Advances in Control Systems, University of Vienna.

Parker, C., and A. Evans. 2007. Inside Lawyers' Ethics. Cambridge: Cambridge University Press.

Pasquale, F. 2014. "The Emperor's New Codes: Reputation and Search Algorithms in the Finance Sector." Draft for discussion at the NYU Governing Algorithms conference. http://governingalgorithms.org/wp-content/uploads/2013/05/2paper-pasquale.pdf.

Pasquale, F. 2015. The Black Box Society: The Secret Algorithms that Control Money and Information. Cambridge, MA: Harvard University Press.

Pilz, M., and L. Zenner. 2018. "Using Case Studies in Business Education to Promote Networked Thinking: Findings of an Intervention Study." Teaching in Higher Education 23 (3): 325-342.

Prince, J. M., and M. R. Felder. 2006. "Inductive Teaching and Learning Methods: Definitions, Comparisons, and Research Bases." Journal of Engineering Education 95: 123-138.

Pritchard, M. 1992. "Cutting Roadside Trees." In Teaching Engineering Ethics: A Case Study Approach, Michigan: Center for the Study of Ethics in Society National Science Foundation, University of Michigan.

Raju, P. K., and C. S. Sankar. 1999. "Teaching Real-World Issues Through Case Studies." Journal of Engineering Education 88 (4): 501-508.

Reed, R., and R. J. DeFillippi. 1990. "Causal Ambiguity, Barriers to Imitation, and Sustainable Competitive Advantage." Academy of Management Review 15: 88-102.

Richards, L. G., M. Gorman, W. T. Scherer, and R. D. Landel. 1995. "Promoting Active Learning with Cases and Instructional Modules." Journal of Engineering Education 84 (4): 375-381.

Shallcross, D. 2013. "Safety Education Through Case Study Presentations." Education for Chemical Engineers 8: e12-e30.

Shuman, L. J., M. F. Sindelar, M. Besterfield-Sacre, H. Wolfe, R. Pinkus, R. L. Miller, B. M. Olds, and C. Mitcham. 2004. “Can Our Students Recognize and Resolve Ethical Dilemmas?" In American Society for Engineering Education Annual Conference and Exposition. Salt Lake City, UT.

Simons, P. 2011. "Ontology in Engineering." In Philosophy of Engineering (2), 21-25. London: The Royal Academy of Engineering.

Simons, P. 2013. "Varieties of Parthood: Ontology Learns from Engineering." In Philosophy and Engineering: Reflections on Practice, Principles and Process, edited by D. Michelfelder, N. McCarthy, and D. Goldberg, 151-163. Dordrecht: Springer.

Stephan, K. 2001-2002. "Is Engineering Ethics Optional?" IEEE Technology and Society Magazine 20 (9): 6-12.

Swanson, D. A., and P. A. Morrison. 2010. "Teaching Business Demography Using Case Studies." Population Policy Review 29 (1): 93-104.

Tai, D. 2013. "Engineering Ethics, STS, and the China Airlines Cl-611 Accident." East Asian Science, Technology and Society 7 (4): 579-599. Duke University Press.

Thiel, C. E., S. Connelly, L. Harkrider, L. Devenport, Z. Bagdasarov, J. F. Johnson, and M. D. Mumford. 2013. “Case-Based Knowledge and Ethics Education: Improving Learning and Transfer Through Emotionally Rich Cases." Science and Engineering Ethics 19 (1): 265-286.

Thistlethwaite, J. E., D. Davies, S. Ekeocha, J. M. Kidd, C. Macdougall, P. Matthews, et al. 2012. "The Effectiveness of CaseBased Learning in Health Professional Education. A BEME Systematic Review." BEME Guide 23 (34): 421-444.

Thomas, M., F. O'Connor, M. Albert, D. Boutain, and P. A. Brandt. 2001. "Case-Based Teaching and Learning Experiences." Issues in Mental Health Nursing 22 (5): 517-531.

Tripp, D. 2005. "Action Research: A Methodological Introduction." Educação e Pesquisa 31 (3): 443-466.

Umoja Noble, S. 2018. Algorithms of Oppression: How Search Engines Reinforce Racism. New York: New York University Press.

van der Burg, S., and A. van Gorp. 2005. "Understanding Moral Responsibility in the Design of Trailers." Science and Engineering Ethics 11 (2): 235-256.

Vaughan, D. 1996. The Challenger Launch Decision. Chicago: University of Chicago Press. 
Vermaas, P., P. Kroes, I. van de Poel, M. Franssen, and W. Houkes. 2011. A Philosophy of Technology: From Technical Artefacts to Sociotechnical Systems, Synthesis Lectures on Engineers, Technology and Society, Morgan \& Claypool.

Verrax, F. 2017. "Engineering Ethics and Post-Normal Science: A French Perspective." Futures 91: 76-79.

Vincenti, W. G. 1990. How Engineers Know and How They Know It. Baltimore: Johns Hopkins University Press.

Walling, O. 2015. "Beyond Ethical Frameworks: Using Moral Experimentation in the Engineering Ethics Classroom." Science and Engineering Ethics 21 (6): 1637-1656.

Williams, S. M. 1992. "Putting Case-Based Instruction Into Context: Examples From Legal and Medical Education." The Journal of Learning Sciences 2 (4): 367-427.

Wilson, W. R. 2013. "Using the Chernobyl Incident to Teach Engineering Ethics." Science and Engineering Ethics 19 (2): 625-640.

Winner, L. 1986. "Do Artifacts Have Politics?" In The Whale and the Reactor: A Search for Limits in an Age of High Technology, edited by L. Winner, 19-39. Chicago: University of Chicago Press.

Winner, L. 1990. "Engineering Ethics and Political Imagination." In Broad and Narrow Interpretations of Philosophy of Technology. Philosophy and Technology (7), edited by P. T. Durbin, 53-64. Dordrecht: Springer.

Yadav, A., and B. E. Barry. 2009. "Using Case-Based Instruction to Increase Ethical Understanding in Engineering: What do We Know? What Do We Need?" International Journal of Engineering Education 25 (1): 138-143.

Yadav, A., M. Lundeberg, M. DeSchryve, K. Dirkin, N. A. Schiller, K. Maier, and C. F. Herreid. 2007. "Teaching Science with Case Studies: A National Survey of Faculty Perceptions of the Benefits and Challenges of Using Case Studies." Journal of College Science Teaching 37 (1): 34-38.

Zandvoort, H., G. J. Van Hasselt, and J. A. B. A. F. Bonnet. 2008. "A Joint Venture Model of Teaching Required Courses in 'Ethics and Engineering' to Engineering Students." European Journal of Engineering Education 33 (2): 187-195. 